\title{
Edwardsiella tarda Outer Membrane Protein C: An Immunogenic Protein Induces Highly Protective Effects in Flounder (Paralichthys olivaceus) against Edwardsiellosis
}

\author{
Fuguo Liu ${ }^{1}$, Xiaoqian Tang ${ }^{1}$, Xiuzhen Sheng ${ }^{1}$, Jing Xing ${ }^{1}$ and Wenbin Zhan ${ }^{1,2, *}$ \\ 1 Laboratory of Pathology and Immunology of Aquatic Animals, Ocean University of China, 5 Yushan Road, \\ Qingdao 266003, China; aquamedic@ouc.edu.cn (F.L.); tangxq@ouc.edu.cn (X.T.); xzsheng@ouc.edu.cn (X.S.); \\ xingjing@ouc.edu.cn (J.X.) \\ 2 Laboratory for Marine Fisheries Science and Food Production Processes, Qingdao National Laboratory for \\ Marine Science and Technology, No. 1 Wenhai Road, Aoshanwei Town, Jimo, Qingdao 266071, China \\ * Correspondence: wbzhan@ouc.edu.cn; Tel.: +86-532-8203-2284
}

Academic Editor: Li Lin

Received: 6 June 2016; Accepted: 7 July 2016; Published: 12 July 2016

\begin{abstract}
Outer membrane protein C of Edwardsiella tarda is a major cell surface antigen and it was identified to be an immunogenic protein by Western blot using flounder (Paralichthys olivaceus) anti-recombinant $\mathrm{OmpC}(\mathrm{rOmpC})$, and anti-E. tarda antibodies. rOmpC tested the immune protective effect against $E$. tarda challenge in a flounder model and produced a relative percentage of survival rate of $85 \%$. The immune response of flounder induced by rOmpC was investigated, and the results showed that: (1) the levels of specific serum antibodies induced by rOmpC were significantly higher than the control group after the second week after immunization, and the peak level occurred at week five after immunization; (2) rOmpC could induce the proliferation of sIg+ lymphocytes, and the peak levels of sIg+ lymphocytes in blood, spleen, and pronephros occurred at 4-5 weeks after immunization; and (3) the MHCII $\alpha, C D 4-1, I L-1 \beta, I L-6$ and TNF- $\alpha$ genes were significantly induced after being injected with rOmpC. Taken together, these results demonstrated that rOmpC could evoke highly protective effects against $E$. tarda challenge and induce strong innate immune response and humoral immune response of flounder, which indicated that $\mathrm{OmpC}$ was a promising vaccine candidate against $E$. tarda infection.
\end{abstract}

Keywords: outer membrane protein C; Edwardsiella tarda; vaccine; flounder; immune response

\section{Introduction}

Edwardsiella tarda is a Gram-negative pathogen and the etiological agent of edwardsiellosis, which affects a wide range of marine and freshwater fish [1-3], causing enormous economic losses around the world [4,5]. The common method to treat edwardsiellosis is by administration of antibiotics, which would cause environmental pollution and microbial resistance [6]. Vaccines have advantages in safety, environmental friendliness, and long-term efficacy of protection [7], and they have gradually become a mainstream product in disease prevention in aquaculture.

Outer membrane protein $C$ is a porin that resides in the outer membrane of Gram-negative bacteria. Studies in human pathogen Escherichia coli and Salmonella typhi had showed that OmpC is a major cell surface antigen, and the expression of OmpC during the infection period and its capacity of exhibiting heterologous epitopes on the cell surface make it an attractive candidate antigen in vaccine development [8-11]. Research has confirmed that OmpC of pathogenic E. coli, when in form of subunit vaccine, could induce the production of specific serum antibodies and produce highly 
protective effects against E. coli infection and cross-protection against Shigella strains [12]. It was also reported that OmpC of Salmonella revealed better protection against virulent Salmonella challenge when compared with formalin-killed, whole-cell bacterial vaccine in a bird model [13,14]. Moreover, a Shigella flexneri 3a OmpC epitope was recognized by human umbilical cord sera and associated with protective activity, mice immunized with OmpC retained long-lasting protection against a lethal dose of both homologous and heterologous strains of the pathogens [15]. Additionally, OmpC in other Gram-negative bacteria, such as Aeromonas hydrophila and S. enterica serovar Typhi, has also been reported to have the potential in vaccine development $[9,16]$. E. tarda is a pathogen bacteria that threatens fish, reptiles, amphibians, and humans [17], and great efforts have been directed into vaccine development during the last decade. Though several effective subunit vaccine candidates have been obtained [18], no commercializable subunit vaccine is available. Moreover, frequently outbreaks of edwardsiellosis have highlighted the urgent need to develop a highly protective vaccine. Thus, the values of OmpC in vaccine design against pathogens of human and higher vertebrates may shed light for us to develop a highly protective vaccine against $E$. tarda.

In the present study, OmpC of E. tarda was amplified and recombinantly expressed. To test the immunogenicity of OmpC, outer membrane proteins of $E$. tarda were extracted and analyzed by Western blot using flounder (Paralichthys olivaceus) anti-rOmpC and anti-E. tarda antibodies. Meanwhile, the immune response of flounder after being injected with $\mathrm{rOmpC}$ was investigated, including the production of specific serum antibodies, the proliferation of sIg+ lymphocytes and the expression of immune-related genes. Moreover, the immune protective effects were examined by challenging with E. tarda in the flounder model.

\section{Results}

\subsection{Expression and Purification of Recombinant Outer Membrane Protein C}

OmpC with TRX-tag were expressed in E. coli BL21 (DE3) with pET-32a system (Merck Millipore, Darmstadt, Germany). Sodium dodecyl sulfate-polyacrylamide gel electrophoresis (SDS-PAGE) revealed that OmpC was successfully expressed after IPTG induction with a distinct band representing about $60 \mathrm{kDa}$ (Figure 1), which was in accordance with the predicted molecular mass of OmpC plus TRX protein mass about $21 \mathrm{kDa}$ [19]. After purification with the $\mathrm{Ni}^{2+}$ affinity chromatography, the rOmpC with high purity were obtained.

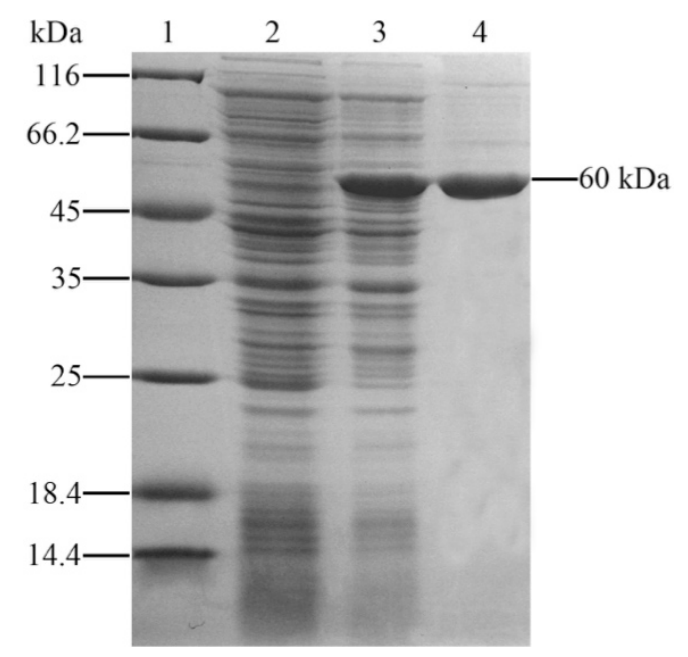

Figure 1. SDS-PAGE analysis of rOmpC. Lane 1: molecular mass marker; Lane 2: negative control without IPTG induction; Lane 3: E. coli transfected with pET-32a-OmpC induced with IPTG; Lane 4: purified protein of rOmpC. 


\subsection{Analysis of the Immunogenicity of $\mathrm{OmpC}$}

To test the immunogenicity of OmpC, the OMPs of E. tarda was extracted and analyzed by Western blot using flounder anti-rOmpC and anti-E. tarda antibodies. Interestingly, both of two different antibodies could specifically bind the $37 \mathrm{kDa}$ protein (Figure 2). Mass spectrometric (MS) results showed that the $37 \mathrm{kDa}$ protein matched 4, 2, 3 and 1 peptides with OmpA, OmpC, OmpF, and GAPDH of E. tarda, respectively, and all of them obtained high mascot scores. Details of the MS results are given in Table 1.

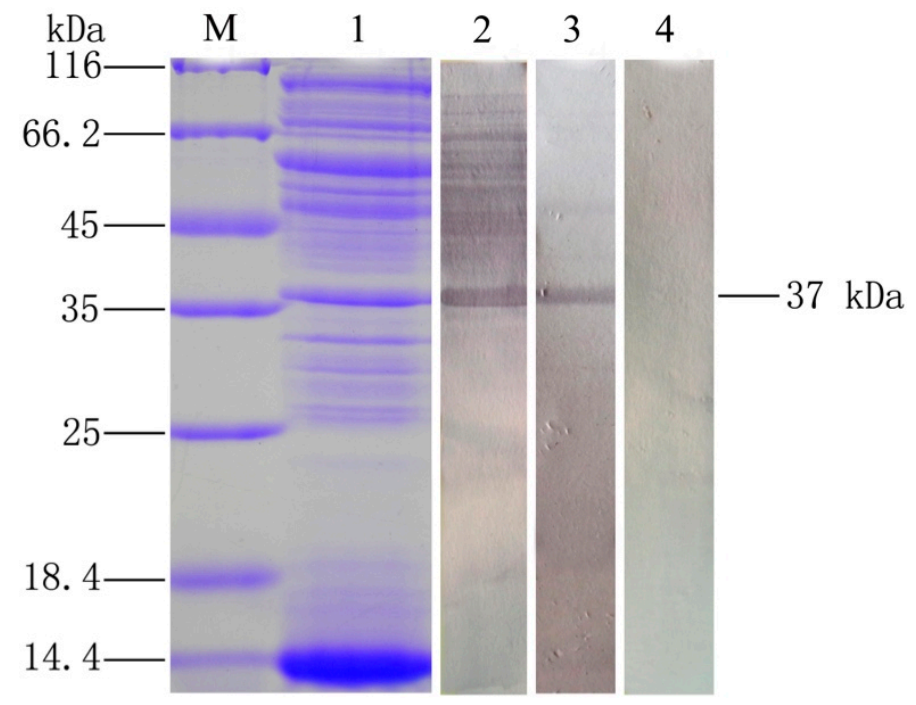

Figure 2. Analysis of the immunogenicity of OmpC by SDS-PAGE and Western blot. Lane M: molecular mass marker; Lane 1: OMPs extracted from E. tarda; Lane 2: Western blot analysis using flounder anti-E. tarda serum; Lane 3: Western blot analysis using flounder anti-rOmpC serum; Lane 4: negative control using the serum of healthy founder.

Table 1. Mass spectrometric results of the $37 \mathrm{kDa}$ protein.

\begin{tabular}{|c|c|c|c|c|c|c|}
\hline Number & Protein Name & Accession No. & Theoretical pI & $\begin{array}{c}\text { Theoretical } \\
M_{\mathrm{W}}(\mathrm{Da})\end{array}$ & $\begin{array}{l}\text { Mascot Score /No. } \\
\text { of Match Peptides }\end{array}$ & $\begin{array}{c}\text { Protein } \\
\text { Coverage }(\%)\end{array}$ \\
\hline 1 & $\begin{array}{l}\text { Outer } \\
\text { membrane } \\
\text { protein A }\end{array}$ & gi | 269138621 & 8.28 & 38057 & $350 / 4$ & 19 \\
\hline 2 & $\begin{array}{c}\text { Outer } \\
\text { membrane } \\
\text { protein C }\end{array}$ & gi | 387867288 & 5.26 & 40872 & $265 / 2$ & 11 \\
\hline 4 & $\begin{array}{l}\text { Glyceraldehyde- } \\
\text { 3-phosphate } \\
\text { dehydrogenase }\end{array}$ & gi I 550649563 & 6.60 & 35567 & $196 / 1$ & 9 \\
\hline
\end{tabular}

\subsection{Flow Cytometric Immunofluorescence Analysis}

The gated lymphocytes in Forward scatter/Sideward scatter dot plot and represented fluorescence histograms of rOmpC-injected fish at week 4 after immunization are shown in Figure 3, and the changes of the percentages of sIg+ lymphocytes in different tissues of vaccinated fish were summarized in Figure 4. Three weeks after immunization, the levels of sIg+ lymphocytes in blood and pronephros of rOmpC-injected fish were significantly increased compared with the control group, and the peak levels occurred at week 5 after immunization. However, the level of sIg+lymphocytes in spleen of rOmpC-injected fish was significantly increased as early as two weeks after immunization compared with the control, and the peak level occurred at week 4 after immunization. 

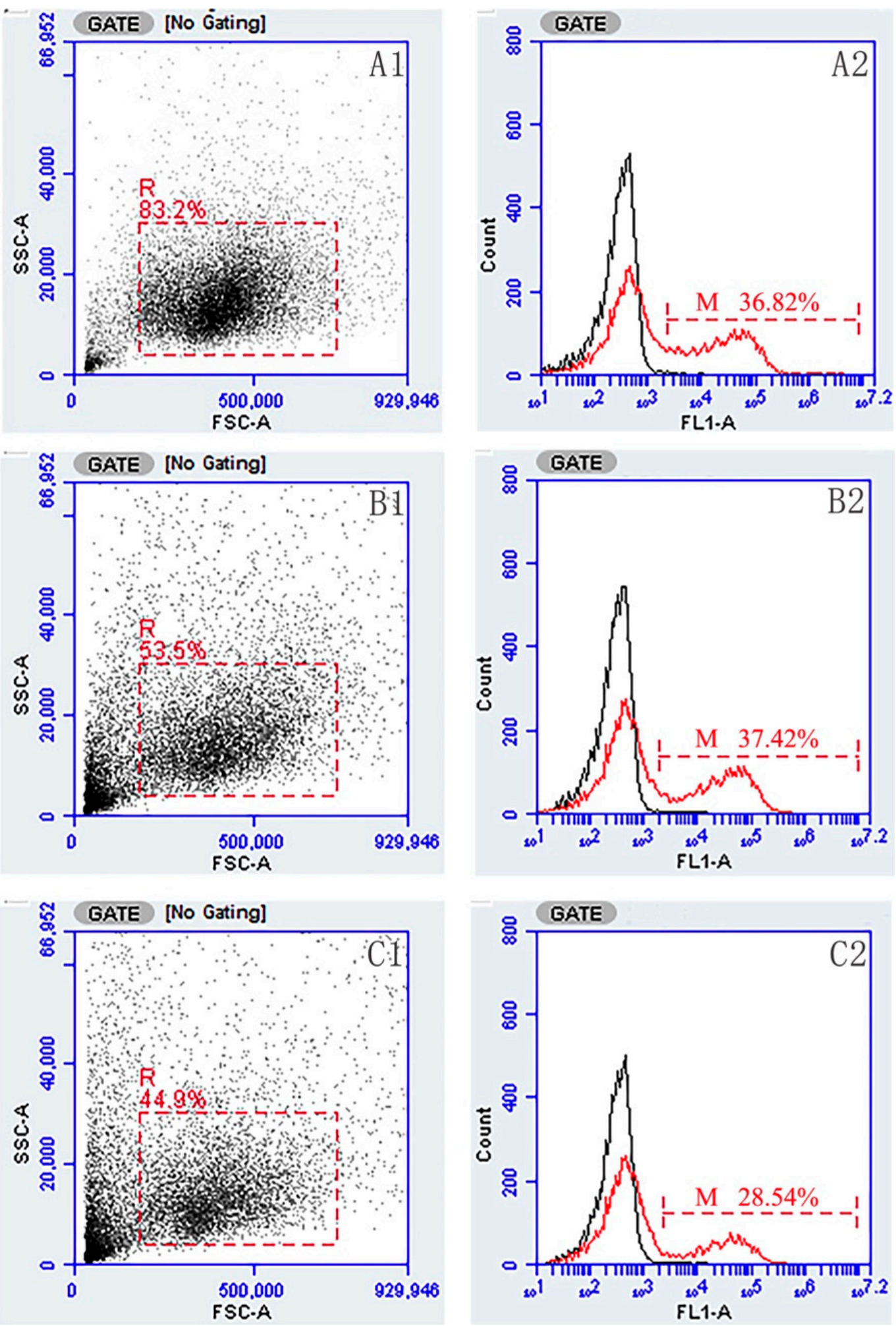

Figure 3. Flow cytometric analysis of lymphocytes reacted with MAb 2D8. A1, B1 and C1 represented lymphocytes in blood, spleen, and pronephros gated (R) on a forward scatter (FSC) versus side scatter (SSC) dot plot, respectively; A2, B2 and C2, rOmpC-injected fish, combined (smoothed) Fluorescein isothiocyanate (FITC) fluorescence histogram of gated lymphocytes (R) showing the percentages of sIg+ lymphocytes (scale of $\mathrm{M}$ ) in blood, spleen, and pronephros at week 4 after immunization, respectively. 

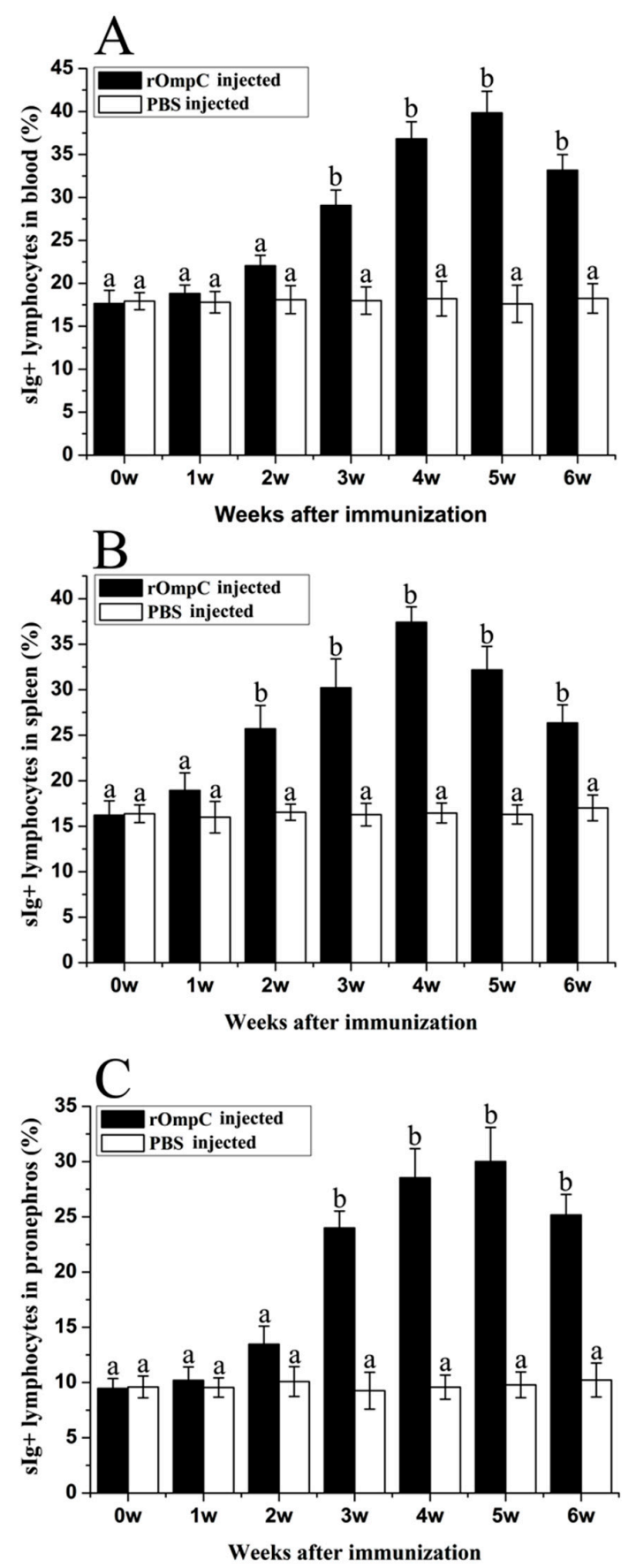

Figure 4. The changes of the levels of sIg+ lymphocytes in blood (A), spleen (B) and pronephros (C) of rOmpC and phosphate-buffered saline (PBS)-injected fish after immunization. Results are expressed as means $\pm \operatorname{SEM}(n=3)$. Different letters " $a$ " and " $b$ " on the bars represent the statistical significance $(p<0.05)$ compared to each other at same time point.

\subsection{Enzyme Linked Immunosorbent Analysis of Sera Antibodies against E. tarda}

ELISA analysis showed that rOmpC could induce the production of specific serum antibodies against $E$. tarda (Figure 5). The levels of specific serum antibodies induced by rOmpC rapidly increased at week 2, 3, and 4 after immunization, and then reached the peak level at week 5 after immunization. The levels of specific serum antibodies of rOmpC group were significantly higher than the control group except the first week after immunization. 


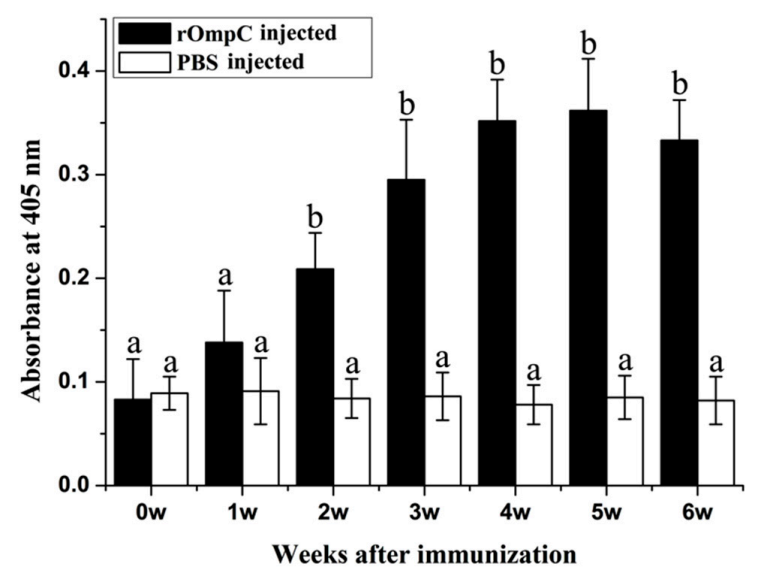

Figure 5. Serum antibodies against $E$. tarda in vaccinated fish. Sera were collected from three fish before immunization and at week 1, 2, 3, 4, 5 and 6 after immunization, serum antibodies against $E$. tarda were determined by ELISA. Results are expressed as means $\pm \operatorname{SEM}(n=3)$. Different letters " $\mathrm{a}$ " and " $\mathrm{b}$ " on the bars represent the statistical significance $(p<0.05)$ compared to each other at same time point.

\subsection{Immune Protective Effects of Recombinant Outer Membrane Protein C}

Before the challenge experiment, no mortality was found in the rOmpC- or PBS-injected groups and no lesions were found on the skin and internal organs of rOmpC- or PBS-injected flounder when sampled at various time points. While the flounders were challenged with live $E$. tarda at six weeks post vaccination, the fish began to die on day 3 after being challenged, and the cumulative mortality rate of the control group increased rapidly at $1-2$ weeks and reached $100 \%$ at day 10 . However, lower cumulative mortality rates were observed in the fish injected with rOmpC compared with the control group. The cumulative mortality rates of all the experimental groups after being challenged with E. tarda are summarized in Figure 6. The results showed that the cumulative mortalities of rOmpC and PBS injected groups were $15 \%$ and $100 \%$, respectively, which correspond to an RPS of $85 \%$ for rOmpC. The infected flounder showed typical clinical signs of edwardsiellosis, including rectal hernia and abdominal distension, opacity of the eye and exophthalmia, and peripheral hyperemia in mandible lesions. Bacterial tests on the infected flounder also demonstrated that $E$. tarda was the pathogen that caused the death of flounder.

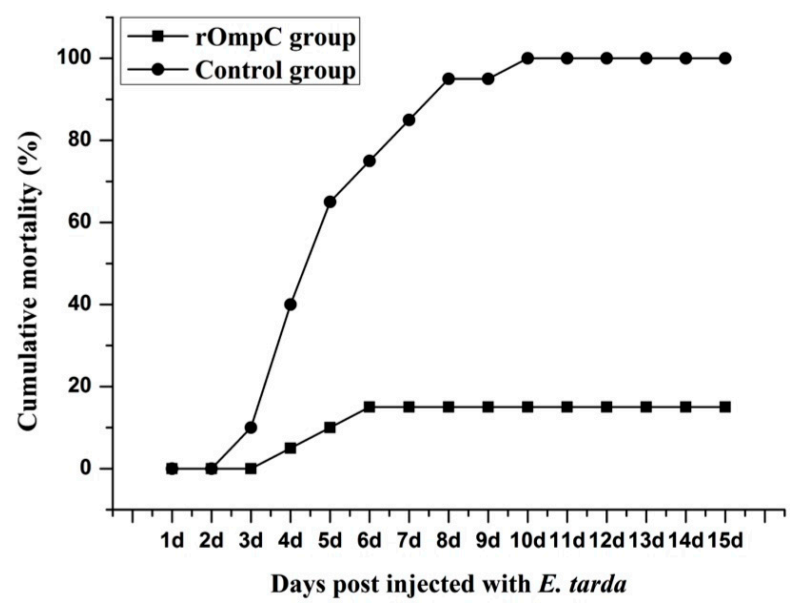

Figure 6. Cumulative mortality of flounder injected with rOmpC or PBS. Six weeks after immunization, all groups were challenged with E. tarda of $10^{7} \mathrm{CFU} /$ fish and the mortalities were recorded for $15 \mathrm{~d}$ until there were no dead fish found. E. tarda was recovered from the liver, spleen and kidney of moribund fish. 


\subsection{Expression of Immune-Related Genes}

qRT-PCR analysis showed that rOmpC could induce the up-regulation of MHCII $\alpha$ CD4-1, IL-1 $\beta$, TNF- $\alpha$ and IL-6. MHCII $\alpha$ gene significantly up-regulated and reached the peaks at day 5 , day 7 and day 5 after immunization in liver, spleen and head kidney, respectively. CD4-1 gene was highly induced by rOmpC and the peaks occurred at day 7 , day 7 and day 14 after immunization in liver, spleen, and head kidney, respectively (Figure 7). The expression of $I L-1 \beta$ and TNF- $\alpha$ shared a similar variation, the mRNA levels increased and reached the peaks at 6-24 $\mathrm{h}$ after immunization, and then declined. IL-6 gene significantly up-regulated and reached the peaks at $24-48 \mathrm{~h}$ after immunization (Figure 8). However, there was no significant difference in expressions of TLR2, TLR5M, IFN- $\gamma, M H C I \alpha$, and $C D 8 \alpha$ genes between the rOmpC-injected and the control group.

(A) MHC $I 1 \alpha$

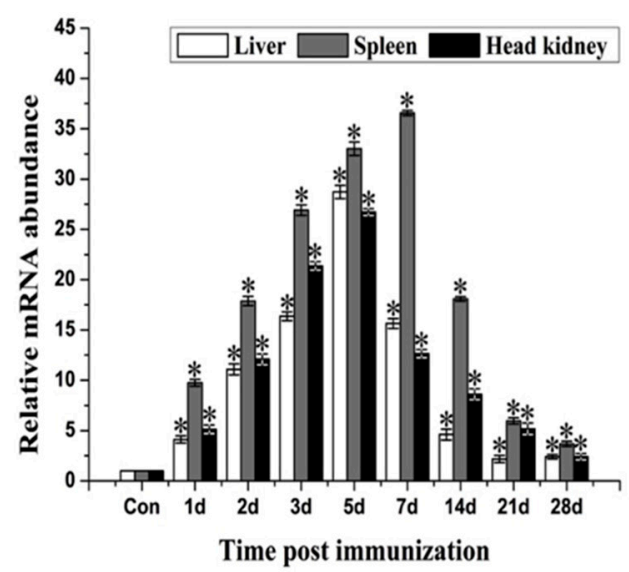

(B) CD4-1

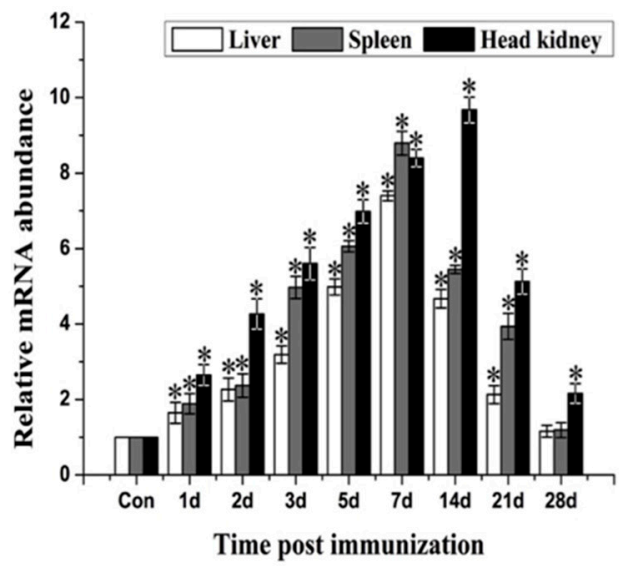

Figure 7. qRT-PCR analysis of the expression of MHCII (A) and CD4-1 (B). The liver, spleen, and head kidney were sampled at 1, 2, 3, 5, 7, 14, 21 and 28 days after immunization. The mRNA level of each immune-related gene was normalized to that of $18 \mathrm{~S}$. For each gene, the mRNA level of the control fish was set as 1. Results are expressed as means $\pm \operatorname{SEM}(n=3)$. The asterisk indicates the statistical significance compared with the control group $\left({ }^{*} p<0.05\right)$.
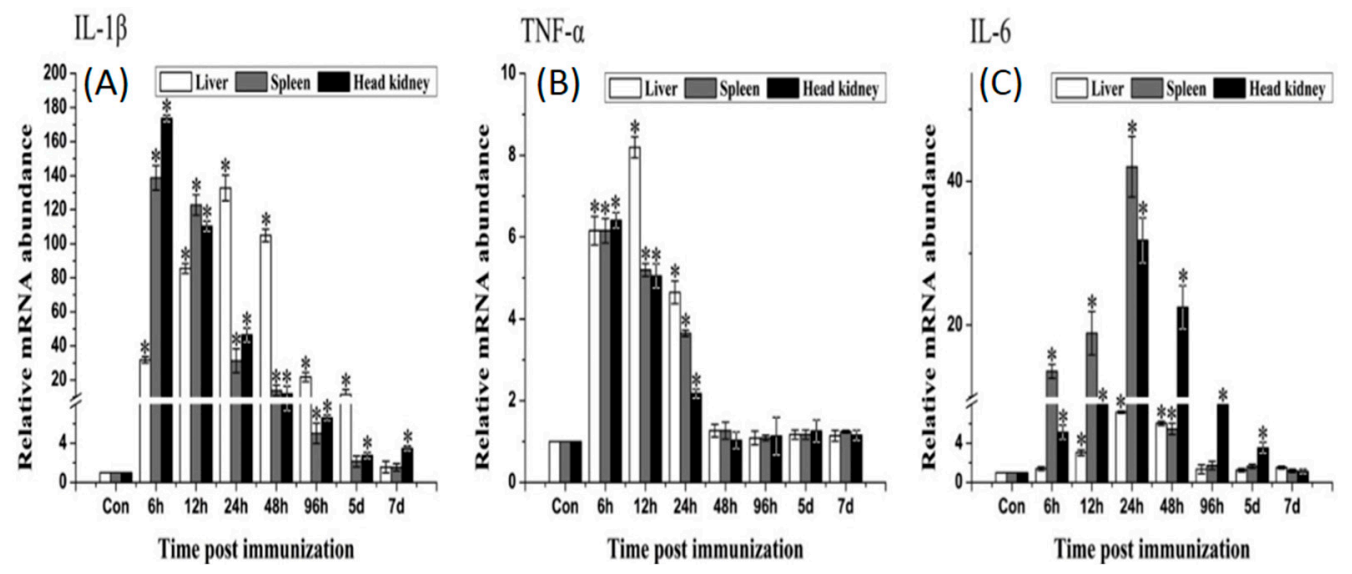

Figure 8. qRT-PCR analysis of the expression of $I L-1 \beta$ (A), TNF- $\alpha$ (B) and IL-6 (C). The liver, spleen, and head kidney were sampled at $6 \mathrm{~h}, 12 \mathrm{~h}, 24 \mathrm{~h}, 48 \mathrm{~h}, 96 \mathrm{~h}, 5$ days and 7 days after immunization. The mRNA levels of each immune-related gene were normalized to those of $18 \mathrm{~S}$. For each gene, the mRNA level of the control fish was set as 1. Results are expressed as means $\pm \operatorname{SEM}(n=3)$. The asterisk indicates the statistical significance compared with the control group $\left({ }^{*} p<0.05\right)$. 


\section{Discussion}

To test the immunogenicity of OmpC, the OMPs of E. tarda were extracted and analyzed by Western blot using flounder anti-rOmpC and anti-E. tarda antibodies. Interestingly, both of two specific antibodies could bind the $37 \mathrm{kDa}$ protein. MS results showed that the $37 \mathrm{kDa}$ protein highly matched with OmpC of E. tarda. These results may indicate that OmpC was an immunogenic protein, which had high abundance in the surface of E. tarda. When flounder was vaccinated with formalin-inactivated $E$. tarda, anti-OmpC antibodies could be effectively induced. Meanwhile, rOmpC could preserve the properties of native OmpC, and antibodies induced by rOmpC could react with native OmpC. Moreover, MS results showed that the $37 \mathrm{kDa}$ protein could also match with OmpA, OmpF, and GAPDH of E. tarda, these might be explained that the $37 \mathrm{kDa}$ protein may have more than one homologues. Previous studies showed that a homologue of the $37 \mathrm{kDa}$ protein, glyceraldehyde-3-phosphate dehydrogenase (GAPDH) when in form of recombinant protein could produce immune-protective effects in flounder against edwardsiellosis [20,21]. OmpC and OmpF were homologs and they shared great similarities in the amino sequence with each other [22-24]. Additionally, OmpA was highly conserved through evolution and rOmpA could highly protect carp against $E$. tarda infection $[25,26]$. These may indicate that all of the four proteins may have the potential to be vaccine candidates.

Subunit vaccines are safe and have negligible adverse effects, several researchers have confirmed that subunit vaccines, when in form of recombinant proteins purified from E. coli and formulated with certain adjuvants, could induce the production of specific serum antibodies and produce highly protective effects [1,27]. In the present study, flounder was injected with $100 \mu \mathrm{L}$ of $2 \mathrm{mg} / \mathrm{mL} \mathrm{rOmpC}$ equally mixed with complete Freund's adjuvant. During a six-week observation period, no mortality was found in the rOmpC-injected group and no lesions were found on the skin and internal organs of rOmpC-injected flounder when sampled at various time points. Moreover, this dose of rOmpC produced an RPS of $85 \%$ against E. tarda challenge. All of these results suggested that OmpC was a protective antigen and $2 \mathrm{mg} / \mathrm{mL}$ rOmpC was a safe dose. Nevertheless, only one concentration was set in the present study, which might not be the most optimal concentration, so we also believed that a further research was needed to optimize the injection dose by setting a series of concentrations. Meanwhile, the levels of sIg+ lymphocytes and specific antibodies induced by rOmpC were also examined. The results showed that rOmpC could induce the proliferation of sIg+ lymphocytes and the peak levels in blood, spleen, and pronephros occurred at week 5 , week 4 and week 5 after immunization. In accordance with the change variation of sIg+ lymphocytes, the specific antibodies increased and reached the peak level at week 5 after immunization. These results may indicate that rOmpC could induce a strong humoral immune response.

It was reported that MHCI and MHCII genes responsible for encoding cell-surface glycoproteins, which will bind foreign peptides and present self- and non-self peptide to T-cells' receptors [28,29]. It was also considered that foreign peptides degraded by intracellular pathogens were presented to cytotoxic CD8+ T cells by MHCI molecule [30], and foreign peptides of extra cellular pathogens were presented to CD4+ T cells by MHCII molecule [31]. In our research, MHCII $\alpha$ and CD4-1 genes significantly up-regulated after immunization, while MHCI $\alpha$ and $C D 8 \alpha$ were not induced. Though E. tarda was an intracellular pathogen [32], OmpC when in form of recombinant protein may be bound by MHCII and presented to CD4+ T cells, which indicate that the recognition and presentation of rOmpC may involve in MHCII and CD4 pathway. Three important pro-inflammatory cytokines, IL-1 $\beta, T N F-\alpha$, and $I L-6$, were also induced by rOmpC. These cytokines play an important role in activating the pro-inflammatory cytokine cascade, in activating the functions of macrophages, and also in activation of the adaptive immune system [33]. TLRs are well known as the key pattern recognition receptors for detecting invading microorganisms [34], however, both TLR2 and TLR5M genes were not induced after vaccination with rOmpC, suggesting that the TLR2 and TLR5 pathways were not activated. 


\section{Materials and Methods}

\subsection{Expression and Purification of Recombinant Outer Membrane Protein C}

Based on the genome sequence of E. tarda EIB202 (Genbank No. CP001135.1), the gene sequence encoding OmpC was obtained and the accession number was ETAE3470. Specific primers were designed to amplify the open reading frame (ORF) of OmpC excluding the region coding for its signal peptide. The primers used were all listed in Table 2. The PCR product of OmpC was purified and digested with specific restriction enzymes, and then ligased into pET-32a vector to construct recombinant plasmids. The recombinant plasmid pET-32a-OmpC was transformed into E. coli BL21 (DE3). The transformant was cultured in LB medium to a mid-logarithmic phase and induced by adding isopropyl $\beta$-D-1-thiogalactopyranoside. His-tagged $\mathrm{rOmpC}$ was purified using His Trap ${ }^{\mathrm{TM}}$ HP Ni-Agarose (GE healthcare China, Beijing, China) followed by the manufacturer's instruction. The purified protein was dialyzed for $24 \mathrm{~h}$ against phosphate-buffered saline (PBS) and treated with Triton X-114 to remove endotoxin [35]. The protein was analyzed by SDS-PAGE and visualized after staining with Coomassie brilliant blue R-250. The concentrations of proteins were determined using the Bradford method.

Table 2. Primers used in this study.

\begin{tabular}{|c|c|c|c|}
\hline Primer No. & Primer Name & Primer Sequence & Source \\
\hline 1 & OmpC-F & 5'-CGAGCTC ATGATGAATAAAATCCGCTC-3' & \multirow[b]{2}{*}{ ETAE3470 } \\
\hline 2 & OmpC-R & 5'-CCGCTCGAGTTAGAACTTATAGTTCAGCATGG-3' & \\
\hline 3 & 18sRNA-F & 5'-GGTCTGTGATGCCCTTAGATGTC-3' & \multirow{2}{*}{ EF126037 } \\
\hline 4 & 18sRNA-R & 5'-AGTGGGGTTCAGCGGGTTAC-3' & \\
\hline 5 & TLR2-F & 5'-CTGCGGTGTAGCGTTAGTGG-3' & \multirow{2}{*}{ AB109393 } \\
\hline 6 & TLR2-R & 5'-CGAAGGCATCATAGGAAAGC-3' & \\
\hline 7 & TLR5M-F & 5'-TCCAGCATCATTACCAA-3' & \multirow{2}{*}{ AB562152 } \\
\hline 8 & TLR5M-R & 5'-TCATACCCAAGTTAGCG-3' & \\
\hline 9 & IL- $1 \beta-F$ & 5'-CTGTCGTTCTGGGCATCAAA-3' & \multirow[b]{2}{*}{ AB720983 } \\
\hline 10 & IL-1 $\beta-R$ & 5'-AACAGAAATCGCACCATCTCACT-3' & \\
\hline 11 & $\mathrm{TNF} \alpha-\mathrm{F}$ & 5'-GTCCTGGCGTTTTCTTGGTA-3' & \multirow{2}{*}{ AB040448 } \\
\hline 12 & $\mathrm{TNF} \alpha-\mathrm{R}$ & 5'-CTTGGCTCTGCTGCTGATTT-3' & \\
\hline 13 & IFN- $\gamma-\mathrm{F}$ & 5'-TGTCAGGTCAGAGGATCACACAT-3' & \multirow{2}{*}{ AB435093 } \\
\hline 14 & IFN- $\gamma-\mathrm{R}$ & 5'-GCAGGAGGTTCTGGATGGTTT-3' & \\
\hline 15 & IL-6-F & 5'-CTCCGCAATGGGAAGGTG-3' & \multirow{2}{*}{ DQ267937 } \\
\hline 16 & IL-6-R & 5'-GATGGATGGGTGGAATAA-3' & \\
\hline 17 & $\mathrm{MHCI} \alpha-\mathrm{F}$ & 5'-AGACCACAGGCTGTTATCACCA-3' & \multirow{2}{*}{ AB126921 } \\
\hline 18 & $\mathrm{MHCI} \alpha-\mathrm{R}$ & 5'-TCTTCCCATGCTCCACGAA-3' & \\
\hline 19 & MHCII $\alpha-F$ & 5'-ACAGGGACGGAACTTATCAACG-3' & \multirow{2}{*}{ AY997530 } \\
\hline 20 & MHCII $\alpha-\mathrm{R}$ & 5'-TCATCGGACTGGAGGGAGG-3' & \\
\hline 21 & CD4-1-F & 5'-CCAGTGGTCCCCACCTAAAA-3' & \multirow{2}{*}{ AB643634 } \\
\hline 22 & CD4-1-R & 5'-CACTTCTGGGACGGTGAGATG-3' & \\
\hline 23 & $\mathrm{CD} 8 \alpha-\mathrm{F}$ & 5'-ССТСТССССАТАСАTTGATTCС-3' & \multirow{2}{*}{ AB082957 } \\
\hline 24 & $\mathrm{CD} 8 \alpha-\mathrm{R}$ & 5'-CCGAGCTTTGCTGAAGGACTT-3' & \\
\hline
\end{tabular}

\subsection{Preparation of Flounder Anti-rOmpC and Anti-E. tarda Antibodies}

Ten healthy flounder weights of $750 \pm 50 \mathrm{~g}$ were purchased from local farm and divided randomly into two groups and were immunized via intraperitoneal injection with rOmpC or inactivated E. tarda mixed with complete Freund's adjuvant. The flounder were boosted with the same amount of rOmpC or inactivated E. tarda mixed with incomplete Freund's adjuvant at two weeks after the initial immunization. The fish were sacrificed at two weeks post the last boost, and blood was collected from the caudal veins of the fish. The blood was placed at $4{ }^{\circ} \mathrm{C}$ for overnight to allow clotting, and sera were obtained by centrifugation at $3000 \times g$ for $10 \mathrm{~min}$ [36], and then the serum 
was stored at $-20^{\circ} \mathrm{C}$ until usage. Before manipulations, the fish were anaesthetized with $100 \mathrm{ng} / \mathrm{mL}$ of tricaine methanesulphonate (MS-222, Sigma, St. Louis, MO, USA). For euthanasia, the fish were over-anesthetized with $300 \mathrm{ng} / \mathrm{mL}$ of MS-222.

\subsection{Analysis of the Immunogenicity of $\mathrm{OmpC}$}

The OMPs of E. tarda were extracted by the method as described [37]. The extracted OMPs were analyzed by SDS-PAGE and transferred onto a PVDF membrane (Merck Millipore, Darmstadt, Germany). The membrane was blocked with PBS containing $4 \%$ BSA for $1 \mathrm{~h}$ at $37{ }^{\circ} \mathrm{C}$, and incubated with flounder anti-rOmpC serum, anti-E. tarda serum or the serum of healthy flounder for $1 \mathrm{~h}$ at $37^{\circ} \mathrm{C}$, then washed three times with PBS containing $0.05 \%$ Tween-20 (PBST), and then incubated with $\mathrm{mAb} 2 \mathrm{D} 8$ for $1 \mathrm{~h}$ at $37^{\circ} \mathrm{C}$, which was a monoclonal antibody against flounder IgM previously produced by our laboratory [38], then washed three times with PBST. Antibody binding was detected with goat-anti-mouse Ig-alkaline phosphatase conjugate (Merck Millipore, Darmstadt, Germany) diluted 1:4000 in PBS for $1 \mathrm{~h}$ at $37^{\circ} \mathrm{C}$, and washed three times with PBST. Finally, the bands were stained with freshly prepared substrate solution $(100 \mathrm{mM} \mathrm{NaCl}, 100 \mathrm{mM}$ Tris and $5 \mathrm{mM} \mathrm{MgCl} 2, \mathrm{pH} 9.5$ ) containing nitroblue tetrazolium (NBT, Sigma, St. Louis, MO, USA) and 5-bromo-4-chloro-3-indolyphosphate (BCIP, Sigma, St. Louis, MO, USA) for 5 min and stopped by washing with distilled water. The immune-reactive proteins were excised from polyacrylamide gels and analyzed by an ABI5800 matrix-assisted laser desorption ionization time-of-flight (MALDI-TOF) assay system (Applied Biosystems, Beverly, MA, USA).

\subsection{Vaccination and Sampling}

Two hundred healthy flounder with body weights of $30 \pm 5 \mathrm{~g}$ were obtained from a fish farm in Rizhao City of Shandong province, China. The fish were maintained in tanks containing aerated, sand-filtered seawater at $21 \pm 0.5^{\circ} \mathrm{C}$ for one week prior to processing. Flounder were equally divided into two groups. For rOmpC vaccination, the concentration of rOmpC was adjusted to $2 \mathrm{mg} / \mathrm{mL}$, and one group was intraperitoneally injected with $100 \mu \mathrm{L} \mathrm{rOmpC}$ mixed with complete Freund's adjuvant at equal volume. The other one was intraperitoneally injected with $100 \mu \mathrm{L}$ PBS as the control group.

The serum and the lymphocytes in blood, spleen, and pronephros were randomly sampled from three fish in each group before immunization and at week 1, 2, 3, 4, 5 and 6 after immunization. For serum isolation, blood was collected from the caudal veins and allowed to clot overnight at $4{ }^{\circ} \mathrm{C}$. The serum was obtained by centrifugation at $3000 \times g$ for $10 \mathrm{~min}$ and stored at $-20^{\circ} \mathrm{C}$ until usage. For qRT-PCR, the liver, spleen, and head kidney were randomly collected from three fish in each group at $6 \mathrm{~h}, 12 \mathrm{~h}, 24 \mathrm{~h}$ ( 1 day), $48 \mathrm{~h}$ ( 2 days), $72 \mathrm{~h}$ ( 3 days), $96 \mathrm{~h}$ (4 days), 5 days, 7 days, 14 days, 21 days and 28 days after immunization. Tissues were placed in a sample protector (Baosheng, Dalian, China) and stored at $-80^{\circ} \mathrm{C}$ until usage. Before manipulations, the fish were anaesthetized or over-anaesthetized with MS-222 as before.

\subsection{Flow Cytometric Immunofluorescence Analysis}

The lymphocytes in blood, spleen, and pronephros of vaccinated flounder were isolated according to the technique as described in our previous study [38]. The lymphocytes in PBS were counted and diluted to $1 \times 10^{6}$ cells $/ \mathrm{mL}$, then incubated with mAb 2D8 (1:3000 diluted in PBS) for $1 \mathrm{~h}$ at $37^{\circ} \mathrm{C}$. Subsequently, cells were washed three times with PBS containing $5 \%(v / v)$ Newborn Calf Serum, then incubated with goat-anti-mouse Ig-FITC (1:256 diluted in PBS, Sigma) for $1 \mathrm{~h}$ at $37^{\circ} \mathrm{C}$, and washed again. After that, the cell suspensions were analyzed with an Accuri C6 cytometer (BD Accuri ${ }^{\mathrm{TM}}$, Piscataway, NJ, USA).

\subsection{Detection of the Serum Antibodies against E. tarda by ELISA}

Wells of flat-bottom microplates (96-wells, Costar) were coated overnight with $100 \mu \mathrm{L} /$ well of E. tarda $\left(10^{8} \mathrm{CFU} / \mathrm{mL}\right)$ at $4{ }^{\circ} \mathrm{C}$. The wells were washed three times with PBST and then blocked with $3 \%$ 
BSA in PBS for $1 \mathrm{~h}$ at $37^{\circ} \mathrm{C}$. After washing, the serum (1:100 diluted in PBS) sampled from vaccinated fish at different times were added $100 \mu \mathrm{L}$ per well and incubated for $2 \mathrm{~h}$ at $37^{\circ} \mathrm{C}$. Following washing, $100 \mu \mathrm{L} \mathrm{mAb} 2 \mathrm{D} 8$ (1:3000 diluted in PBS) was added for serum antibody detection. After incubation at $37^{\circ} \mathrm{C}$ for $1 \mathrm{~h}$ and washing, $100 \mu \mathrm{L}$ goat-anti-mouse Ig-alkaline phosphatase conjugate (Sigma) diluted 1:5000 in PBS was added and incubated for $1 \mathrm{~h}$ at $37^{\circ} \mathrm{C}$. After the last washing, $100 \mu \mathrm{L} 0.1 \%$ $(w / v)$ p-nitrophenyl phosphate (pNPP, Sigma, USA) in $50 \mathrm{mM}$ carbonate-bicarbonate buffer ( $\mathrm{pH} 9.8)$ containing $0.5 \mathrm{mM} \mathrm{MgCl}_{2}$ was added to each well and incubated at room temperature for $30 \mathrm{~min}$ in the dark. The reaction was stopped by adding $50 \mu \mathrm{L}$ per well of $2 \mathrm{M} \mathrm{NaOH}$ and absorbance was measured with an automatic ELISA reader (TECAN, Männedorf, Switzerland) at $405 \mathrm{~nm}$.

\subsection{Analysis of the Expression of Immune-Related Genes by qRT-PCR}

Total RNA was extracted from the liver, spleen, and head kidney of vaccinated fish using trizol reagent according to the manufactures' instruction and measured by a Nanodrop 8000 Spectrophotometer (Thermo Scientific, Waltham, MA, USA). Single-strand cDNA was synthesized from $2 \mu \mathrm{g}$ total RNA using PrimeScript ${ }^{\mathrm{TM}}$ RT-PCR Kit (Baosheng, Dalian, China) according to the manufactures' instruction. qRT-PCR was carried out using SYBR GreenI Master (Roche, Basel, Switzerland) in a LightCycler ${ }^{\circledR} 480$ II Real-Time System (Roche, Basel, Switzerland). Each assay was performed in triplicate with $18 \mathrm{~S}$ gene as the internal control. All dates were analyzed relative to the $18 S$ gene by the $2^{-\Delta \Delta C t}$ method, then the difference in the vaccinated and control groups were employed to assess changes in the expression of genes. The primers for TLR2, TLR5M, MHCI $\alpha, M H C I I \alpha$, CD4-1, CD 8 $\alpha, I L-1 \beta, I L-6, I F N-\gamma, T N F-\alpha$ and $18 S$ were listed in Table 2.

\subsection{Challenge}

Forty vaccinated fish were randomly selected from each vaccinated group for challenge test at week 6 after immunization. The E. tarda used for challenge was cultured in LB media at $30^{\circ} \mathrm{C}$ for $24 \mathrm{~h}$. The fish was intraperitoneally injected with a dose of $100 \mu \mathrm{L}$ per fish containing $1 \times 10^{7} \mathrm{CFU}$ live E. tarda. Mortalities were monitored over a period of 15 days after the challenge, and relative percentage of survival rate (RPS) was calculated as previously described [39].

\subsection{Statistical Analysis}

The statistical analysis was performed using Statistical Product and Service Solution (SPSS) software (Version 20.0; SPSS, IBM, Armonk, NY, USA), differences were analyzed with one-way analysis of variance (ANOVA) and the results were expressed as mean \pm SEM. In all cases, the significance level was defined as $p<0.05$.

\section{Conclusions}

In conclusion, OmpC of E. tarda is an immunogenic surface protein, which could induce strong innate immune response and humoral immune response in flounder and finally evoke highly protective effects against $E$. tarda challenge when in the form of a recombinant protein. This indicates that OmpC is a promising vaccine candidate against $E$. tarda infection.

Acknowledgments: This study was supported by the National Natural Science Foundation of China (31302216; 31472295), National Basic Research Program of China (2012CB114406), Taishan Scholar Program of Shandong Province, Science and Technology Development Project of Shandong Province (2014GNC111015) and The Scientific and Technological Innovation Project Financially Supported by Qingdao National Laboratory for Marine Science and Technology (No. 2015ASKJ01).

Author Contributions: Fuguo Liu and Wenbin Zhan conceived, designed and carried out the experiments; Xiaoqian Tang, Xiuzhen Sheng and Jing Xing participated in date analysis, coordination and manuscript preparation.

Conflicts of Interest: The authors declare no conflicts of interest. 


\section{References}

1. Wang, C.; Hu, Y.H.; Chi, H.; Sun, L. The major fimbrial subunit protein of Edwardsiella tarda: Vaccine potential, adjuvant effect, and involvement in host infection. Fish Shellfish Immun. 2013, 35, 858-865. [CrossRef] [PubMed]

2. Leung, K.Y.; Siame, B.A.; Tenkink, B.J.; Noort, R.J.; Mok, Y.K. Edwardsiella tarda—Virulence mechanisms of an emerging gastroenteritis pathogen. Microbes Infect. 2013, 14, 26-34. [CrossRef] [PubMed]

3. Matsuyama, T.; Kamaishi, T.; Ooseko, N.; Kurohara, K.; Lida, T. Pathogenicity of motile and non-motile Edwardsiella tarda to some marine fish. Fish. Pathol. 2005, 40, 133-135. [CrossRef]

4. Gao, Y.; Wu, H.Z.; Wang, Q.Y.; Qu, J.B.; Liu, Q.; Xiao, J.F.; Zhang, Y.X. A live attenuated combination vaccine evokes effective immune-mediated protection against Edwardsiella tarda and Vibrio anguillarum. Vaccine 2014, 32, 5937-5944. [CrossRef] [PubMed]

5. Toranzo, A.E.; Magariños, B.; Romalde, J.L. A review of the main bacterial fish diseases in mariculture systems. Aquaculture 2005, 246, 37-61. [CrossRef]

6. Xu, T.; Zhang, X.H. Edwardsiella tarda: An intriguing problem in aquaculture. Aquaculture 2014, 431, $129-135$. [CrossRef]

7. Sun, K.; Zhang, W.W.; Hou, J.H.; Sun, L. Immunoprotective analysis of VhhP2, a Vibrio harveyi vaccine candidate. Vaccine 2009, 27, 2733-2740. [CrossRef] [PubMed]

8. Arockiasamy, A.; Murthy, G.S.; Rukmini, M.R.; Sundara Baalaji, N.; Katpally, U.C.; Krishnaswamy, S. Conformational epitope mapping of OmpC, a major cell surface antigen from Salmonella typhi. J. Struct. Biol. 2004, 148, 22-23. [CrossRef] [PubMed]

9. Kumar, P.D.; Krishnaswamy, S. Overexpression, refolding, and purification of the major immunodominant outer membrane porin OmpC from Salmonella typhi: Characterization of refolded OmpC. Protein Express. Purif. 2005, 40, 126-133. [CrossRef] [PubMed]

10. Puente, J.L.; Alvarez-Scherer, V.; Gosset, G.; Calva, E. Comparative analysis of the Salmonella typhi and Escherichia coli OmpC genes. Gene 1989, 83, 197-206. [CrossRef]

11. Puente, J.L.; Juárez, D.; Bobadilla, M.; Arias, C.F.; Calva, E. The Salmonella OmpC gene: Structure and use as a carrier for heterologous sequences. Gene 1995, 156, 1-9. [CrossRef]

12. Wang, X.; Guan, Q.F.; Wang, X.M.; Teng, D.; Mao, R.Y.; Yao, J.H. Paving the way to construct a new vaccine against Escherichia coli from its recombinant outer membrane protein $\mathrm{C}$ via a murine model. Process. Biochem. 2015, 50, 1194-1201. [CrossRef]

13. Agarwal, R.K.; Porteen, K.; Dubal, Z.B.; Asha, K.; Shweta, S.; Ripan, B. Evaluation of recombinant outer membrane protein based vaccine against Salmonella Typhimurium in birds. Biologicals 2013, 41, 162-168.

14. Lee, H.; Kim, S.; Kim, K.; Mo, I.; Woo, Y.; Kwon, Y. Immunogenicity of outer membrane protein extracted from Salmonella gallinarum in chickens. Natl. Vet. Res. Inst. 1997, 37, 555-568.

15. Jarząb, A.; Witkowska, D.; Ziomek, E.; Dabrowska, A.; Szewczuk, Z.; Gamain, A. Shigella flexneri 3a outer membrane protein $C$ epitope is recognized by human umbilical cord sera and associated with protective activity. PLoS ONE 2013, 8, e70539. [CrossRef] [PubMed]

16. Yadav, S.K.; Sahoo, P.K.; Dixit, A. Characterization of immune response elicited by the recombinant outer membrane protein OmpF of Aeromonas hydrophila, a potential vaccine candidate in murine model. Mol. Biol. Rep. 2014, 41, 1837-1848. [CrossRef] [PubMed]

17. Janda, J.; Abbott, S. Infectious associated with the genus Edwardsiella: The role of Edwardsiella tarda in human disease. Clin. Infect. Dis. 1993, 17, 742-748. [PubMed]

18. Park, S.B.; Aoki, T.; Jung, T.S. Pathogenesis of and strategies for preventing Edwardsiella tarda infection in fish. Vet. Res. 2012, 43, 67. [CrossRef] [PubMed]

19. Xu, G.J.; Zhan, W.B.; Ding, B.J.; Sheng, X.Z. Molecular cloning and expression analysis of polymeric immunoglobulin receptor in flounder (Paralichthys olivaceus). Fish Shellfish Immun. 2013, 35, 653-660. [CrossRef] [PubMed]

20. Liu, Y.; Oshima, S.; Kurohara, K.; Ohnishi, K.; Kawai, K. Vaccine efficacy of recombinant GAPDH of Edwardsiella tarda against edwardsiellosis. Microbiol. Immunol. 2005, 49, 605-612. [CrossRef] [PubMed]

21. Kawai, K.; Liu, Y.; Ohnishi, K.H.; Oshima, S.I. A conserved $37 \mathrm{kDa}$ outer membrane protein of Edwardsiella tarda is an effective vaccine candidate. Vaccine 2004, 22, 3411-3418. [CrossRef] [PubMed] 
22. Pongprayoon, P. How do the protonation states of E296 and D312 in OmpF and D299 and D315 in homologous OmpC affect protein structure and dynamics? Simulation studies. Comput. Biol. Chem. 2014, 53, 226-234. [CrossRef] [PubMed]

23. Kumar, A.; Hajjar, E.; Ruggerone, P.; Ceccarelli, M. Structural and dynamical properties of the porins OmpF and OmpC: Insights from molecular simulations. J. Phys. 2010, 22, 454125. [CrossRef] [PubMed]

24. Biró, I.; Pezeshki, S.; Weingart, H.; Winterhalter, M.; Kleinekathöfer, U. Comparing the temperature-dependent conductance of the two structurally similar E. coli porins OmpC and OmpF. Biophys. J. 2010, 98, 1830-1839. [CrossRef] [PubMed]

25. Maiti, B.; Shetty, M.; Shekar, M.; Karunasagar, I.; Karunasagar, I. Recombinant outer membrane protein A (OmpA) of Edwardsiella tarda, a potential vaccine candidate for fish, common carp. Microbiol. Res. 2011, 167, 1-7. [CrossRef] [PubMed]

26. Jeannin, P.; Magistrelli, G.; Goetsch, L.; Haeuw, J.F.; Thieblemont, N.; Bonnefoy, J.Y. Outer membrane protein $\mathrm{A}(\mathrm{OmpA})$ : A new pathogen-associated molecular pattern that interacts with antigen presenting cells-Impact on vaccine strategies. Vaccine 2002, 20, 23-27. [CrossRef]

27. Sun, Y.; Liu, C.; Sun, L. Identification of an Edwardsiella tarda surface antigen and analysis of its immunoprotective potential as a purified recombinant subunit vaccine and a surface-anchored subunit vaccine expressed by a fish commensal strain. Vaccine 2010, 28, 6603-6608. [CrossRef] [PubMed]

28. Croisetiere, S.; Tarte, P.D.; Bernatchez, L.; Belhumeur, P. Identification of MHC class II $\beta$ resistance/susceptibility alleles to Aeromonas salmonicida in brook charr (Salvelinus fontinalis). Mol. Immunol. 2008, 45, 3107-3116. [CrossRef] [PubMed]

29. Xu, T.; Chen, S.; Zhang, Y. MHC class II $\alpha$ gene polymorphism and its association with resistance/susceptibility to Vibrio anguillarum in Japanese flounder (Paralichthys olivaceus). Dev. Comp. Immunol. 2010, 34, 1042-1050. [CrossRef] [PubMed]

30. Srisapoome, P.; Ohira, T.; Hirono, I.; AOKI, T. Cloning, characterization and expression of cDNA containing major histocompatibility complex class I, II $\alpha$ and II $\beta$ genes of Japanese flounder Paralichthys olivaceus. Fish. Sci. 2004, 70, 264-276. [CrossRef]

31. Kjøglum, S.; Larsen, S.; Bakke, H.G.; Grimholt, U. How specific MHC class I and class II combinations affect disease resistance against infectious salmon anaemia in Atlantic salmon (Salmo salar). Fish Shellfish Immun. 2006, 21, 431-441. [CrossRef] [PubMed]

32. Pressley, M.E.; Phelan, P.E.; Witten, P.E.; Mellon, M.T.; Kim, C.H. Pathogenesis and inflammatory response to Edwardsiella tarda infection in the zebrafish. Dev. Comp. Immunol. 2005, 29, 501-513. [CrossRef] [PubMed]

33. Taechavasonyoo, A.; Hirono, I.; Kondo, H. The immune-adjuvant effect of Japanese flounder Paralichthys olivaceus IL-1ß. Dev. Comp. Immunol. 2013, 41, 564-568. [CrossRef] [PubMed]

34. Yang, D.H.; Liu, Q.; Ni, C.S.; Li, S.; Wu, H.Z.; Wang, Q.Y.; Xiao, J.F.; Zhang, Y.X. Gene expression profiling in live attenuated Edwardsiella. tarda vaccine immunized and challenged zebrafish: Insights into the basic mechanisms of protection seen in immunized fish. Dev. Comp. Immunol. 2013, 40, 132-141. [CrossRef] [PubMed]

35. Aida, Y.; Pabst, M.J. Removal of endotoxin from protein solutions by phase separation using Triton X-114. J. Immunol. Methods 1990, 132, 191-195. [CrossRef]

36. Tang, X.Q.; Zhan, W.B.; Sheng, X.Z.; Chi, H. Immune response of Japanese flounder Paralichthys olivaceus to outer membrane protein of Edwardsiella tarda. Fish Shellfish Immun. 2010, 28, 333-343. [CrossRef] [PubMed]

37. Huntley, J.F.; Robertson, G.T.; Norgard, M.V. Method for the isolation of Francisella tularensis outer membranes. J. Vis. Exp. 2010, 40, e2044. [CrossRef] [PubMed]

38. Li, Q.; Zhan, W.B.; Xing, J.; Sheng, X.Z. Production, characterization and applicability of monoclonal antibodies to immunoglobulin of Japanese flounder (Paralichthys olivaceus). Fish Shellfish Immun. 2007, 23, 982-990. [CrossRef] [PubMed]

39. Amend, D.F. Potency testing of fish vaccines. International symposium on fish biologics: Serodiagnostics and vaccines. Dev. Biol. Stand. 1981, 49, 447-454.

(C) 2016 by the authors; licensee MDPI, Basel, Switzerland. This article is an open access article distributed under the terms and conditions of the Creative Commons Attribution (CC-BY) license (http:/ / creativecommons.org/licenses/by/4.0/). 